\title{
Projeção do preço da arroba do boi gordo no estado de São Paulo utilizando modelos lineares dinâmicos
}

\author{
Projection of the cattle arroba price in the state of São Paulo using \\ dynamic linear models \\ Marina Louza Palmeira de Carvalho (1), João Felema' (1) \\ 'Pecege, Escola Superior de Agricultura "Luiz de Queiroz" (ESALQ), Universidade de São Paulo (USP), Piracicaba (SP), Brasil. \\ E-mail: marinalouza@hotmail.com, joaofelema@usp.br
}

\begin{abstract}
Como citar: Carvalho, M. L. P., \& Felema, J. (2022). Projeção do preço da arroba do boi gordo no estado de São Paulo utilizando modelos lineares dinâmicos. Revista de Economia e Sociologia Rural, 60(spe), e249166. https://doi. org/10.1590/1806-9479.2021.249166
\end{abstract}

\begin{abstract}
Resumo: A pecuária de corte no Brasil tem se tornado cada vez mais competitiva, levando o país a ser o segundo maior produtor e o maior exportador mundial de carne bovina. Dessa forma, é relevante analisar o comportamento do preço da arroba do boi gordo, assim como dos fatores que o influenciam, pois tal compreensão auxilia no planejamento estratégico e nas tomadas de decisões dos stakeholders desse setor. O presente estudo aborda o comportamento do preço da arroba do boi gordo no estado de São Paulo no período de janeiro de 2005 a janeiro de 2020, com o objetivo de estimar a projeção da tendência desse preço por meio dos modelos lineares dinâmicos (MLD). Além disso, selecionaram-se previamente, com base na literatura existente, variáveis de mercado para a análise da correlação delas com o valor da arroba do boi gordo. Verificou-se uma forte correlação positiva com o preço do bezerro, a relação de troca bo gordo/boi magro, o abate de bovinos e a importação de carne brasileira pela China. Houve também uma correlação positiva moderada quanto ao volume de exportação de carne bovina pelos Estados Unidos e uma correlação negativa moderada do preço da arroba em reais com a taxa de câmbio do dólar americano.
\end{abstract}

Palavras-chave: pecuária de corte, tendência de preços, modelos lineares dinâmicos.

\begin{abstract}
Beef cattle in Brazil has become increasingly competitive, as the country is the second-largest producer and the largest exporter of beef in the world. It is relevant to analyze the behavior of the price of the cattle arroba in this sector, as well as the factors that influence it, considering that such knowledge helps in the strategic planning and decision-making of the parties involved. This study addresses the verification of the behavior of arroba prices in the state of São Paulo from January 2005 to January 2020 to estimate the projection of the trend of this indicator inquiring the use of the Dynamic Linear Models (DLM). In addition, market variables were previously selected based on the existing literature for the analysis of their correlation with the value of the arroba. There was a strong positive correlation with the price of the calf, the exchange ratio of fat cattle/lean cattle, the slaughter of cattle, and the importation of Brazilian meat by China. There was also a moderate positive correlation regarding the volume of beef exports by the United States and a moderate negative correlation between the arroba price in Brazilian reais and the US dollar exchange rate.
\end{abstract}

Keywords: beef cattle, price trend, dynamic linear models.

\section{INTRODUÇÃO}

A bovinocultura de corte é um setor de grande relevância para a economia do Brasil. Em 2018, o Produto Interno Bruto (PIB) da pecuária brasileira atingiu $R \$ 597,22$ bilhões, isto é, 8,3\% superior ao apurado em 2017, representando 8,7\% do PIB total do país, segundo a Associação Brasileira das Indústrias Exportadoras de Carnes (ABIEC). No mesmo ano, houve um crescimento de $6,9 \%$ na quantidade de abates e um aumento de $12,8 \%$ no volume da produção de carne bovina, sendo $20,4 \%$ da produção exportada e $79,6 \%$ direcionada ao 
mercado interno, responsável por um consumo médio per capita de $42 \mathrm{~kg}_{\text {ano-1 }}$ (Associação Brasileira das Indústrias Exportadoras de Carne, 2019).

Os preços médios da arroba do boi gordo de 2009 a 2019 apresentaram um crescimento de 15,32\% (valores corrigidos pelo IGP-DI), conforme o indicador do Centro de Estudos Avançados em Economia Aplicada (CEPEA/B3). No entanto, considerando os vários fatores que influenciam a formação desse preço, sua estimativa é complexa (Centro de Estudos Avançados em Economia Aplicada, 2020b).

No Brasil, uma arroba equivale a cerca de 15 quilogramas, que se refere ao peso da carcaça, ou seja, o peso da carne com osso, sem considerar os subprodutos, como o sebo, o couro e o casco, que são utilizados para outras finalidades. Normalmente, a negociação da carne bovina é feita em arroba, sendo que o preço da arroba do boi é definido pelas condições de mercado; dessa forma, os produtores e a agroindústria processadora utilizam diferentes estratégias para se protegerem das volatilidades desse indicador. Além disso, o mercado de carne bovina no Brasil possui características peculiares, apresentando ciclos com períodos de alta e baixa dos preços, o que reforça a importância das técnicas de previsão de preço para a orientação dos agentes desse mercado (Ferreira et al., 2000).

Modelos estatísticos capazes de estimar com razoável precisão o preço da arroba do boi gordo vêm sendo cada vez mais utilizados nos estudos empíricos e pelo mercado. Esses modelos de previsão, que podem ser univariados (séries temporais) ou métodos multivariáveis (causais), são alimentados por variáveis que buscam dar respostas aos estudos e ao negócio. Entre os fatores que influenciam de forma direta ou indireta a cotação da arroba do boi gordo, pode-se destacar o preço do boi magro, do bezerro, da vaca gorda e das respectivas relações de troca (Medeiros, 2006).

Diante desse contexto, o objetivo geral do presente artigo é verificar a projeção da tendência do preço da arroba do boi gordo no curto prazo com o uso de modelos lineares dinâmicos (MLD). Em um campo mais específico, buscou-se analisar a correlação desse indicador com outras variáveis da agropecuária e do mercado.

Neste trabalho, utilizar-se-ão os MLD para fazer a projeção do preço da arroba do boi gordo, considerando a base histórica do CEPEA/B3 no período de janeiro de 2005 a janeiro de 2020 (Centro de Estudos Avançados em Economia Aplicada, 2020a).

Este artigo é composto por mais quatro seções, além desta introdução, que compõe a primeira. Na segunda, apresenta-se, de forma sucinta, a literatura relacionada; na terceira, indicam-se a metodologia e os dados utilizados na análise; na quarta, descrevem-se e discutemse os resultados deste trabalho; e, por fim, na quinta, conclui-se o artigo.

\section{FUNDAMENTAÇÃO TEÓRICA}

\subsection{Características da bovinocultura no Brasil}

A cadeia de produção da carne bovina apresenta uma vasta heterogeneidade, envolvendo desde pequenos pecuaristas até grandes pecuaristas especializados, assim como frigoríficos de pequeno a grande porte (Buainain \& Batalha, 2007). Essa cadeia pode ser dividida em cinco elos: insumos, produção de matéria-prima (que envolve a cria, recria e engorda de bovinos), indústria, comercialização e, por fim, consumidor final (Malafaia, 2013).

De acordo com Pires (2011), esses elos podem ser classificados em três etapas: "antes da porteira", referente aos insumos; "dentro da porteira", no que tange à produção da matériaprima; e "depois da porteira", que engloba a indústria, a comercialização e o consumidor final. 
Em relação às fases da atividade pecuária, Sachs \& Pinatti (2007) fazem o seguinte detalhamento:

a) Cria - diz respeito à reprodução e ao crescimento dos bezerros até o desmame.

b) Recria - etapa em que os pecuaristas fazem a aquisição e recriam os bezerros desmamados, produzindo bois magros.

c) Engorda - fase em que os bois magros são engordados até chegar ao peso ideal para o abate, isto é, torna-se o produto pronto para ser comercializado, sendo o boi gordo.

Sachs \& Pinatti (2007) mencionam que os pecuaristas podem atuar em uma das três fases, conforme a sua estrutura de negócio, como uma unidade especializada. Ainda, há produtores que atuam nas três fases de forma conjunta, realizando o que é denominado de ciclo completo (Ávila, 2015). Quando o animal já está com o peso ideal para o abate, realiza-se a venda para a indústria frigorífica.

Conforme Santos et al. (2009), o rebanho é dividido em: bezerro(a), novilho(a), garrote, touro, boi e vaca. O filhote recém-nascido da vaca até os 12 meses de idade é denominado bezerro (macho) ou bezerra (fêmea). Após o desmame, o bezerro é classificado como novilho, cujo período de vida vai de 13 meses até o abate, e a bezerra, como novilha, tornando-se vaca após a primeira parição. O garrote (tourinho) é o macho inteiro desde o desmame até a entrada na reprodução, quando, com 2 a 3 anos de idade, passa a ser classificado como touro. Já o boi é o bovino adulto acima de 3 anos e castrado, destinado a trabalhos agrícolas (Marion, 2016).

Há basicamente três tipos de sistemas utilizados para engorda dos animais: extensivo, semiintensivo e intensivo, sendo que o sistema semi-intensivo é pouco utilizado (Cezar et al., 2005). Os sistemas extensivos são caracterizados por fazer uso de pastagens nativas e cultivadas como única fonte de alimento animal, sendo realizada a fertilização do solo para restituir os elementos que os bovinos retiram das plantas durante o pastejo (Lazzarini Neto, 2000). De acordo com os dados da Empresa Brasileira de Pesquisa Agropecuária (2019), aproximadamente 95\% da carne bovina é produzida em regime de pastagem por causa da grande extensão territorial do Brasil. Isso permite que os custos de produção sejam menores, no entanto vale ressaltar que as pastagens são deficientes em determinados minerais, necessários à nutrição animal. O pecuarista deverá buscar produtividade satisfatória por meio do manejo apropriado que irá permitir o ganho de peso por unidade de área de forma eficiente. Dessa forma, as pastagens mais produtivas têm capacidade para mais cabeças de gado por área, proporcionando maior lucro (Lazzarini Neto, 2000).

O sistema intensivo compreende o uso de confinamentos para a engorda do boi. Segundo Cezar et al. (2005), o objetivo do confinador é obter um ciclo de engorda mais curto, por meio da suplementação animal. O confinamento normalmente ocorre desde antes do período da seca, em maio, até o início do período chuvoso, no final do ano. Entretanto, o período de concentração acontece entre junho e outubro, no auge do período da seca, sendo o prazo médio do giro de confinamento em torno de 90 dias. É um sistema fechado, os alimentos e a água são fornecidos em cocho, e as principais fontes energéticas são o milho e o sorgo. O potencial genético é um fator importante no que tange à capacidade de consumo e à taxa de conversão alimentar (Thiago \& Costa, 1994).

Quanto às características dos bovinos criados no Brasil, em torno de 80 a $90 \%$ dos animais são zebuínos, predominando a raça Nelore. As outras raças, como os de sangue europeu, especialmente Angus e Hereford, estão mais concentradas no Rio Grande do Sul. Além disso, a região Centro-Norte do país está aumentando a quantidade de cruzamento industrial da raça Nelore com raças europeias, principalmente o Angus (Teixeira \& Hespanhol, 2014). 


\subsection{Formação do preço da arroba do boi gordo}

No processo produtivo da bovinocultura, Medeiros \& Montevechi (2005) relatam que as duas principais variáveis que influenciam a produção bovina são: a qualidade dos pastos (que é dependente do clima) e a eficiência produtiva (velocidade de crescimento/engorda do gado), sendo fatores determinantes nas variações dos preços do produto.

Com relação à qualidade dos pastos, observa-se o efeito do ciclo intra-anual ou ciclo de curto prazo. Ainda segundo Medeiros \& Montevechi (2005), entre os meses de outubro e março (período das águas), há uma maior quantidade de forrageira disponível para os animais, o que contribui para a manutenção do gado no pasto para o processo de engorda, acarretando o aumento do preço do bovino por causa da retração da oferta nesse período. No período de seca, acontece o contrário, já que o sistema produtivo dominante no Brasil é a pecuária extensiva, a qual depende das pastagens. Desse modo, os períodos de chuva e estiagem influenciam a qualidade e a disponibilidade de pastagem, o que dificulta a adequação do número de animais nos pastos, visto que uma quantidade superior ao aceitável durante os períodos de estiagem poderia gerar uma redução de peso dos animais, o que seria refletido nos preços do setor.

Conforme o Anuário da Pecuária Brasileira (Instituto FNP, 2015), a duração do ciclo pecuário completo é de aproximadamente quatro anos. No entanto, em razão das inovações tecnológicas no setor da pecuária de corte, como as melhorias no manejo de animais, o melhoramento genético e a suplementação alimentar, a precocidade dos animais tem diminuído significativamente, acarretando uma menor duração desse ciclo. A oscilação do preço do boi gordo está ligada à lei da oferta e da procura, presente de forma cotidiana nas negociações da aquisição dessa matéria-prima. A lei da oferta e da procura influencia os valores por causa da quantidade de produto que está disponível em determinado período versus a demanda do mercado. Nesse sentido, se aumentar a oferta de boi gordo no mercado, o preço tenderá a diminuir; se ocorrer o contrário, o preço tenderá a aumentar (Gaio et al., 2005). Todavia, também existem outros fatores que devem ser analisados na formação do preço.

Algumas variáveis que podem afetar o nível do preço recebido pelo pecuarista, desde os relacionados à produção, como clima, quantidade de pastagem e preço dos insumos já mencionados -, até aqueles relacionados aos consumidores, como preço de produtos substitutos e variáveis macroeconômicas (taxa de juros, taxa cambial, inflação e renda), que afetam a demanda do produto. A carne de frango é a principal substituta da carne bovina, isto é, as oscilações em seu preço podem afetar o consumo e o preço da arroba do boi gordo (Zen et al., 2008).

Segundo Sabadin (2006), aproximadamente $80 \%$ da produção de carne bovina é destinada a abastecer o mercado interno. Números mais recentes fornecidos pela Associação Brasileira das Indústrias Exportadoras de Carne (2019) corroboram esse fato. No entanto, projeções do agronegócio brasileiro para 2029, elaboradas pela Federação das Indústrias do Estado de São Paulo (2020), apontam que o país passará das 6,9 milhões de toneladas embarcadas em 2019 para 10,36 milhões de toneladas em 2029, somando-se os volumes exportados de carne bovina, suína e de frango, ou seja, há a tendência de aumentar o volume de exportação de proteínas.

Além disso, dados do relatório da Food and Agriculture Organization of the United Nations (2015) indicam que os países desenvolvidos irão diminuir a produção de carne bovina, enquanto países em desenvolvimento irão aumentar seu market share para $60 \%$ da produção mundial. Ainda conforme o relatório da Food and Agriculture Organization of the United Nations (2015), até 2023 os países líderes em importação de carne brasileira (China, Rússia, Venezuela e Irã) 
deverão aumentar a demanda em 2,3 milhões de toneladas (34\%), chegando a 9,1 milhões de toneladas.

\section{METODOLOGIA}

Nesta seção, apresentam-se os MLD e as métricas de avaliação para os modelos propostos. Em seguida, indica-se a metodologia de correlação cruzada utilizada para análise da correlação de variáveis selecionadas com o preço da arroba do boi gordo. Por fim, descrevem-se as fontes de dados da pesquisa.

\subsection{Modelos lineares dinâmicos}

Para a realização da projeção de tendência de séries históricas, Medeiros (2006) aponta que os métodos de previsão podem ser divididos em métodos univariados (séries temporais) e métodos multivariáveis (causais).

Os métodos univariados se baseiam apenas em série temporal da variável em questão, utilizando-se do padrão dos dados presentes nas séries históricas para prever valores futuros (DeLurgio, 1998), não considerando a influência de variáveis independentes. Entre os métodos univariados, podem-se citar os MLD, utilizados por Bressan \& Lima (2002) e por Bressan (2004) para o estudo dos preços da arroba do boi gordo.

Os MLD se diferenciam do modelo autorregressivo integrado de médias móveis (ARIMA) por permitir mudanças nos parâmetros, à medida que ocorrem evoluções na série temporal estudada (Bressan \& Lima, 2002).

Conforme Bressan \& Lima (2002), nos MLD, a série $Y t$ é decomposta em termos da tendência $\left(\mu_{t}\right)$, ciclo $\left(\Psi_{t}\right)$, sazonalidade $\left(\gamma_{t}\right)$ e de um componente irregular $\left(\varepsilon_{t}\right)$, isto é, conforme a Equação 1:

$\mathrm{Y}_{\mathrm{t}}=\mu_{\mathrm{t}}+\psi_{\mathrm{t}}+\gamma_{\mathrm{t}}+\varepsilon_{\mathrm{t}}$

A operacionalização do modelo é obtida utilizando-se do modelo de espaço de estados, que o atualiza para novas observações, e do filtro de Kalman, de 1960, para a atualização sequencial dos componentes não observáveis a cada instante de tempo.

Diante dessa abordagem, o modelo de espaço de estados é descrito a partir de um MLD, dividindo-o em duas equações. A primeira, denominada equação das medidas ou das observações, é dada pela Equação 2:

$\mathrm{Y}_{\mathrm{t}}=\mathrm{F}_{\mathrm{t}} \theta_{\mathrm{t}}+v_{\mathrm{t}}$

em que: $F_{t}$ é um vetor $m x 1$ conhecido para todo $t=1, \ldots, m$; e $v_{t}$ é o ruído branco gaussiano. A segunda equação, denominada equação do sistema ou de transição, que representa a evolução dinâmica do vetor de estado $\theta_{t}(m x)$ ), é dada pela Equação 3:

$\theta_{\mathrm{t}}=\mathrm{G}_{\mathrm{t}} \theta_{\mathrm{t}-1}+\omega_{\mathrm{t}}$

em que: $G_{t}$ é uma matriz; $m x m$ é conhecida para todo $\mathrm{t}=1, \ldots, m$; e $\omega_{t}$ é o ruído branco gaussiano. Para o ajuste da série temporal em questão, três modelos foram propostos:

${ }_{1}$ Como ferramenta para processamento dos dados, utilizou-se do ambiente estatístico R Development Core Team, versão 3.5 . 
a) Modelo 1 - local: o modelo MLD polinomial de primeira ordem é conhecido também como modelo de nível local, composto pelo passeio aleatório mais ruído. A função de previsão desse modelo é constante, sendo que, por esse motivo, o modelo também é chamado de modelo estável.

b) Modelo 2 - tendência: já o modelo MLD polinomial de segunda ordem é conhecido também como modelo de tendência linear local. De acordo com Petris et al. (2009), o vetor de estado é composto por dois elementos $\theta_{t}=\left(\mu_{t}, \beta_{t}\right)^{\prime}$ que descrevem uma reta, em que $\mu_{t}$ é interpretado como o nível local, e $\beta_{t}$, como a taxa de crescimento local. O modelo assume que o nível atual $\mu_{t}$ muda linearmente ao longo do tempo e que a taxa de crescimento também pode evoluir. A função de previsão desse modelo é uma reta, sendo também chamada de crescimento linear.

c) Modelo 3 - tendência e sazonalidade: adicionado ao modelo de tendência linear local, foi considerado o MLD sazonal. Conforme Petris et al. (2009), descreve-se a série introduzindo desvios sazonais de média zero, expressa por diferentes coeficientes $\alpha_{i}$ para os diferentes meses do ano.

Os três modelos foram ajustados por meio do pacote dlm (Petris, 2010) do ambiente estatístico R Development Core Team, versão 3.5 (R Development Core Team, 2015). Como sugestões iniciais de $V$ e $W$, para o cálculo dos modelos propostos, utilizou-se das estimativas de máxima verossimilhança e, após a especificação do modelo com tais estimativas, aplicouse o filtro de Kalman para a atualização sequencial dos componentes não observáveis a cada instante de tempo.

Em seguida, realizaram-se as previsões de 12 meses considerando os três modelos propostos. Para a construção dos MLD, aplicaram-se as premissas que se referem à distribuição do erro, que podem ser avaliadas considerando o erro de previsão $\left(e_{i}=\widehat{y_{\mathrm{i}}}-y_{t}\right)$, e são as seguintes: $e_{i} \sim N(0, \sigma)$ e $\operatorname{cov}\left(e_{i}, e_{i-1}\right)=0$.

\subsection{Métricas de avaliação}

Para a avaliação da acurácia das previsões dos três modelos propostos, consideraram-se três métricas de erro: a Raiz do Erro Quadrático Médio (RMSE), o Erro Médio Absoluto (MAE) e a Média do Erro Absoluto Percentual (MAPE).

Representando a previsão do modelo para o $i$-ésimo mês como $\hat{y} i$, o valor observado como $y i$ e $n$ como o número de previsões realizadas, as métricas são calculadas da seguinte forma (Montgomery et al., 2008), conforme as Equações 4, 5 e 6:

$$
\begin{aligned}
& \text { RMSE }=\sqrt{\frac{1}{n} \sum_{i=1}^{n}\left(\widehat{y_{i}}-y_{i}\right)^{2}} \\
& \text { MAE }=\frac{1}{n} \sum_{i=1}^{n}\left|\widehat{y_{i}-y_{i}}\right| \\
& \text { MAPE }=100 * \frac{1}{n} \sum_{i=1}^{n}\left|\frac{\hat{y}_{i}-y_{i}}{y_{i}}\right|
\end{aligned}
$$


Destaca-se que, por elevar as diferenças entre o previsto e o observado ao quadrado, o RMSE atribui maior peso a erros maiores, enquanto o MAE e o MAPE consideram o valor absoluto do erro de previsão.

\subsection{Correlação cruzada}

Uma forma de avaliar a relação entre as variáveis é utilizar a correlação de Pearson, de 1987, conforme a Equação 7, apresentada a seguir.

$$
\mathrm{r}=\frac{\sum_{\mathrm{i}=1}^{\mathrm{n}}\left(\mathrm{x}_{\mathrm{i}}-\bar{x}\right)\left(\left(\mathrm{y}_{\mathrm{i}}-\bar{y}\right)\right.}{\sqrt{\left[\sum_{\mathrm{i}=1}^{\mathrm{n}}\left(\mathrm{x}_{\mathrm{i}}-\bar{x}\right)^{2}\right]\left[\sum_{\mathrm{i}=1}^{\mathrm{n}}\left(\mathrm{y}_{\mathrm{i}}-\bar{y}\right)^{2}\right]}}
$$

em que: x e y são os valores das duas variáveis analisadas; e n é o número de observações.

O coeficiente $r$ varia no intervalo de $(-1,1)$. O sinal indica a direção da correlação, inversa (negativa) ou direta (positiva), enquanto o valor indica a força da correlação. Quanto mais próximo o coeficiente estiver de -1 ou 1, mais forte é a correlação entre as variáveis. Por outro lado, se a correlação for igual a zero, não existe relação entre as variáveis em estudo.

Entretanto, permite apenas a correlação de um valor com outro valor respectivo, sendo que duas ou mais séries podem estar correlacionadas com determinada defasagem ("deslocamento") no tempo. Assim, calcula-se a correlação entre $x_{i+h}$ e $y_{i}$, tal que $h=0, \pm 1, \pm 2, \ldots, \pm k$ é o "deslocamento". No presente estudo, consideraram-se os seguintes valores de $h=-3,-2,-1,0,1,2,3$.

\subsection{Base de dados}

Com o intuito de realizar uma projeção da tendência do preço da arroba do boi gordo, considerando os preços históricos de janeiro de 2005 até janeiro de 2020², utilizou-se da base de dados referente ao indicador CEPEA/B3, sendo esta deflacionada para a base de janeiro de 2020, de acordo com o IGP-DI divulgado pela Fundação Getulio Vargas (2020).

Além disso, também se avaliou a correlação do preço da arroba do boi gordo com as seguintes séries históricas: preço do bezerro - dados obtidos do Centro de Estudos Avançados em Economia Aplicada (2020a) da Escola Superior de Agricultura Luiz de Queiroz (Esalq), considerando a média do estado de São Paulo; relação de troca boi gordo/boi magro - dados provenientes do Instituto de Economia Agrícola (2019), referente ao estado de São Paulo; abate de bovinos no Brasil (em toneladas) - dados obtidos do Instituto Brasileiro de Geografia e Estatística (2020); importação de carne bovina brasileira pela China (em toneladas) - dados extraídos da Associação Brasileira das Indústrias Exportadoras de Carnes (Associação Brasileira das Indústrias Exportadoras de Carne, 2020); exportação de carne bovina pelos Estados Unidos (em toneladas) - dados coletados no U.S. Meat Export Federation (2019); e, por fim, a cotação do dólar americano - dados extraídos da base do Banco Central do Brasil (2020).

\section{RESULTADOS E DISCUSSÃO}

Esta seção apresenta a análise descritiva da série temporal do preço da arroba do boi gordo, os resultados dos ajustes e da previsão da série estimada por meio dos MLD, assim como a

2 Para modelos univariados, devem-se ter, no mínimo, 50 e, preferencialmente, acima de 100 observações para se realizar a projeção de tendência (Box \& Tiao, 1975). O estudo em questão utilizou 180 meses como base histórica, o que confere credibilidade ao cálculo. 
correlação cruzada de variáveis selecionadas do mercado agropecuário com relação ao valor da arroba do boi gordo.

\subsection{Análise descritiva}

A priori, fez-se uma análise descritiva da série temporal do valor da arroba do boi gordo ao longo do período considerado.

O comportamento do preço nominal, assim como do preço real da arroba do boi gordo desde janeiro de 2005 até janeiro de 2020, é representado na Figura 1.

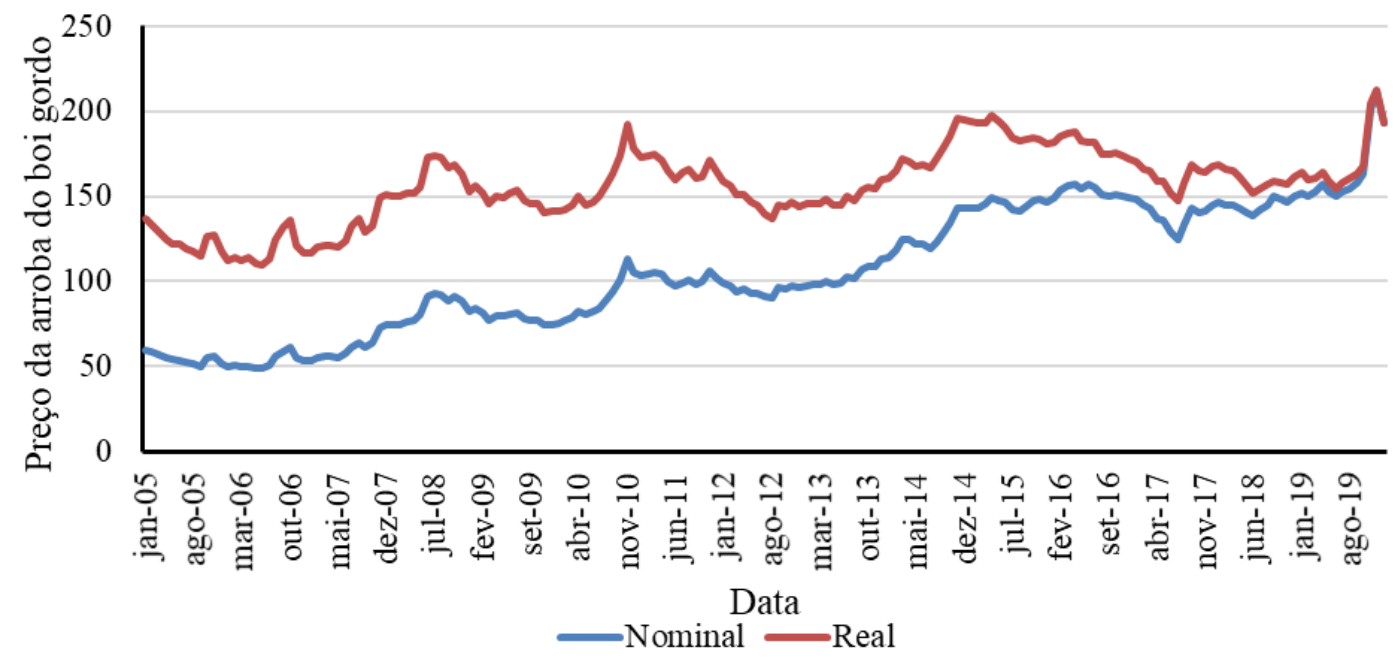

Figura 1. Gráfico de linhas do valor nominal e real da arroba do boi gordo. Fonte: elaborada pelos autores com base nos resultados da pesquisa.

Observa-se que o valor nominal da arroba do boi gordo aumentou ao longo do período considerado, sendo que o máximo de $R \$ 211,97$ foi observado em dezembro de 2019 , enquanto o valor mínimo de $R \$ 48,83$ foi percebido em junho de 2006 . Assim, destaca-se que, de modo geral, os meses que compõem o último trimestre do ano apresentam valores maiores em relação aos demais meses.

Com o intuito de possibilitar a avaliação da série ao longo tempo, a série nominal do valor da arroba do boi gordo foi deflacionada para a base de janeiro de 2020, de acordo com o Índice Geral de Preços - Disponibilidade Interna (IGP-DI), divulgado pela Fundação Getúlio Vargas (2020). Destaca-se que, para a série deflacionada, denominada de valores reais, os meses dos valores máximo e mínimo observados foram mantidos, embora fossem de $R \$ 212,20$ e $R \$$ 109,60, respectivamente. A série real foi utilizada em todas as análises a seguir.

\subsection{Modelos Lineares Dinâmicos}

Adiante, apresentam-se os resultados tanto da previsão quanto do ajuste dos MLD propostos para o valor da arroba do boi gordo. 


\subsubsection{Ajuste}

Calcularam-se três modelos para o ajuste da série temporal referente ao preço da arroba do boi gordo: o modelo 1 se refere ao nível local (Figura 2), o modelo 2 diz respeito à tendência linear local (Figura 3) e, por fim, o modelo 3 adiciona a sazonalidade ao modelo de tendência linear local (Figura 4).

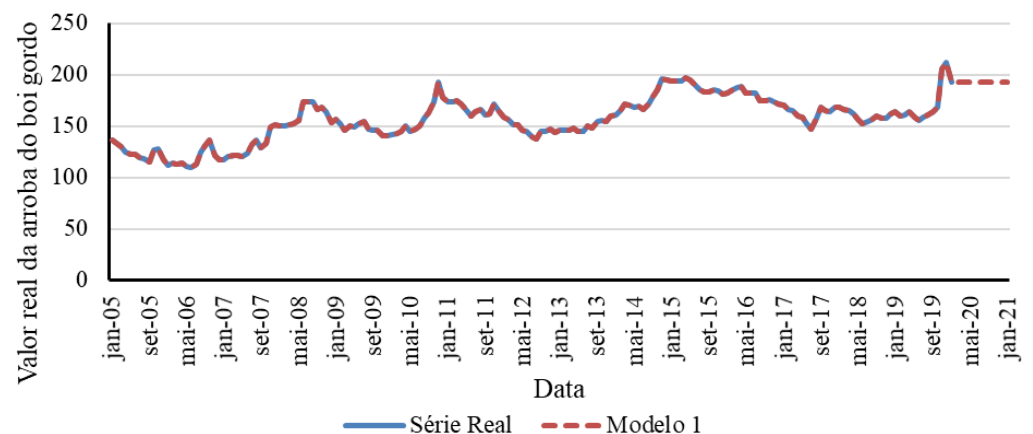

Figura 2. Gráfico de linha do valor real da arroba do boi gordo e ajuste referente ao modelo 1. Fonte: elaborada pelos autores com base nos resultados da pesquisa.

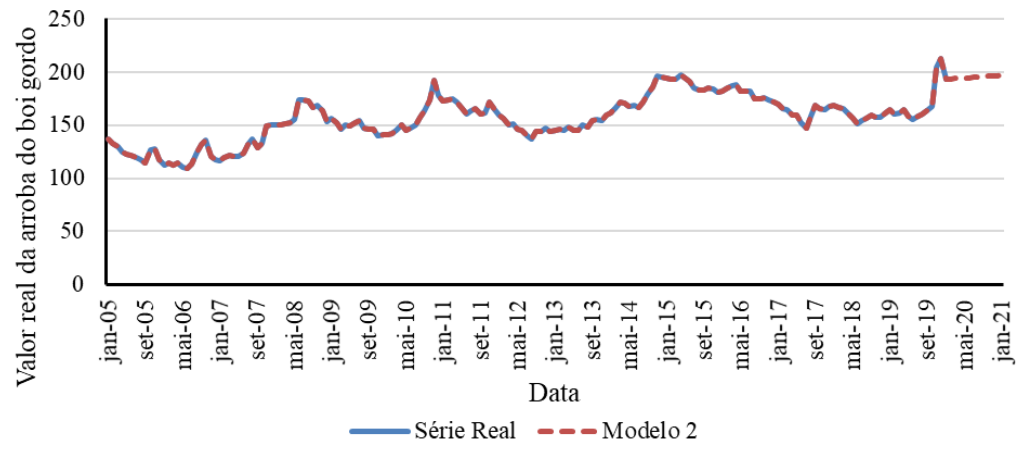

Figura 3. Gráfico de linha do valor real da arroba do boi gordo e ajuste referente ao modelo 2. Fonte: elaborada pelos autores com base nos resultados da pesquisa.

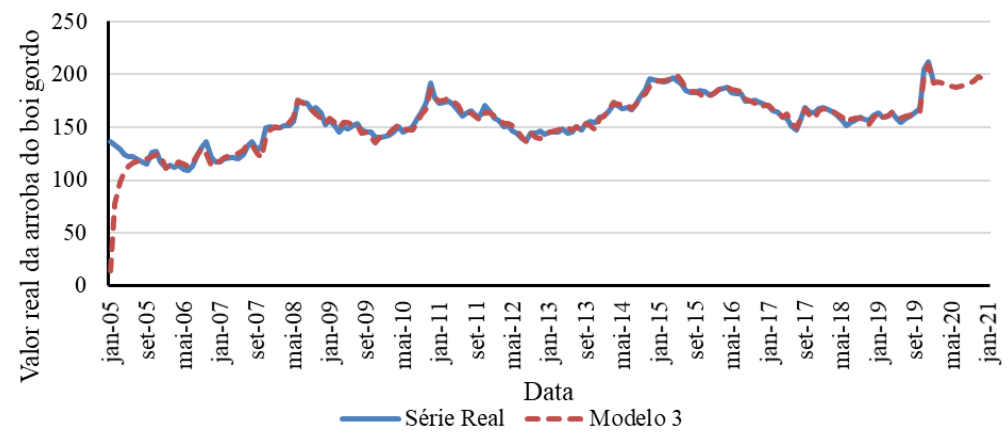

Figura 4. Gráfico de linha do valor real da arroba do boi gordo e ajuste referente ao modelo 3. Fonte: elaborada pelos autores com base nos resultados da pesquisa. 
Observa-se que, apesar da discrepância das estimativas nos primeiros meses no terceiro modelo ${ }^{3}$, os três modelos avaliados apresentam um ajuste próximo aos dados reais. Com o intuito de comparar o ajuste dos modelos, duas medidas de qualidade de ajuste foram calculadas, o Critério de Informação de Akaike (AIC) e o Critério de Informação Bayesiano (BIC), cujos valores são apresentados na Tabela 1.

Tabela 1. Medidas de qualidade de ajuste para os modelos propostos

\begin{tabular}{ccc} 
Modelo & AIC & BIC \\
Modelo 1 & 3235,18 & 3241,57 \\
Modelo 2 & 2320,54 & 2330,14 \\
Modelo 3 & 2289,57 & 2299,16 \\
\hline
\end{tabular}

Fonte: elaborada pelos autores com base nos resultados da pesquisa. Nota: AIC = Critério de Informação de Akaike; $\mathrm{BIC}=$ Critério de Informação Bayesiano.

Para ambos os critérios, quanto menor o valor observado, melhor o ajuste do modelo proposto. Desse modo, vê-se que o modelo 3 apresentou o ajuste mais adequado entre os três modelos considerados, com valores de 2.289,57 e 2.299,16 para as medidas de AIC e BIC, respectivamente.

Ressalta-se que, mesmo após o início do período de ajuste, as estimativas geradas pelo modelo 3 se mostram ligeiramente mais afastadas da série original por causa da presença do coeficiente de sazonalidade, que incorpora a informação da série no mesmo mês dos anos anteriores. Entretanto, a avaliação dos resultados de tais modelos se dá, sobretudo, em relação às previsões, para que essa informação possa prover melhores previsões, mesmo com maior oscilação do ajuste.

\subsubsection{Previsão}

Além dos ajustes, apresentam-se nos gráficos das Figuras 2, 3 e 4 as previsões para os 12 meses subsequentes (período de fevereiro de 2020 a janeiro de 2021) do valor real da arroba do boi gordo.

O modelo 1 (nível local) apresenta previsão constante para todos os 12 meses considerados no valor de $R \$ 193,05$. Já o modelo 2 (tendência) apresenta previsões com um aumento linear de $\mathrm{R} \$ 0,31$ ao mês, sendo que, para o primeiro mês do período (fevereiro de 2020), a previsão foi de $\mathrm{R} \$ 193,36$. No modelo 3 (tendência e sazonalidade), observa-se que a estimativa que se iniciou no valor de $R \$ 192,49$ no mês de fevereiro de 2020 decresceu até $R \$ 188,15$ em junho de 2020, a partir de quando apresentou um aumento até novembro de 2020, atingindo o máximo do período ( $R \$ 197,97)$, e voltou a decrescer.

Em estudo semelhante realizado por Santos \& Gomes (2006), também verificou-se uma queda mais acentuada nos preços da arroba do boi gordo no estado de São Paulo nos meses de março a junho, sendo esse o final do período de maior pluviosidade, ou seja, quando o gado já fez uso da maior disponibilidade de pastagem e acumulou ganhos de peso, gerando um aumento na oferta de animais para abate no mercado. Os maiores preços ocorrem nos meses de setembro a novembro, final do período de menor ocorrência de chuvas em transição para o começo da época mais chuvosa, isto é, quando a disponibilidade de pasto é mais crítica.

\footnotetext{
${ }^{3}$ No terceiro modelo, ainda não se tem sazonalidade refletida nos primeiros meses do ajuste, o que gera um descasamento com relação ao valor real da arroba do boi gordo nesse período.
} 
Nesse momento, os bovinos estão com significativo nível de perda de peso, e os pecuaristas comercializam um menor volume de animais pelas perdas financeiras resultantes.

Destaca-se que, independentemente do modelo, a amplitude do intervalo de confiança torna-se maior conforme a distância do mês de predição com o último mês observado. Todas as previsões e seus respectivos intervalos de confiança são apresentados na Tabela 2, assim como o preço real do período de fevereiro a setembro de 2020, denominado observado 4 .

Tabela 2. Previsões e intervalos de confiança de $95 \%$ dos três modelos propostos

\begin{tabular}{ccccc} 
Data & Modelo 1 & Modelo 2 & Modelo 3 & Observado \\
\hline 01/02/2020 & $193,05(183,31-202,79)$ & $193,36(183,59-203,14)$ & $192,49(182,72-202,27)$ & 197,03 \\
$01 / 03 / 2020$ & $193,05(179,28-206,82)$ & $193,68(179,81-207,54)$ & $192,09(178,45-205,73)$ & 197,09 \\
$01 / 04 / 2020$ & $193,05(176,19-209,91)$ & $193,99(176,97-211,02)$ & $191,98(175,35-208,61)$ & 196,22 \\
$01 / 05 / 2020$ & $193,05(173,58-212,52)$ & $194,31(174,59-214,02)$ & $188,81(169,67-207,94)$ & 195,74 \\
$01 / 06 / 2020$ & $193,05(171,28-214,82)$ & $194,62(172,52-216,72)$ & $188,15(166,83-209,47)$ & 200,94 \\
$01 / 07 / 2020$ & $193,05(169,20-216,90)$ & $194,93(170,66-219,21)$ & $188,80(165,51-212,09)$ & 207,10 \\
$01 / 08 / 2020$ & $193,05(167,29-218,81)$ & $195,25(168,96-221,54)$ & $189,77(164,69-214,85)$ & 205,79 \\
$01 / 09 / 2020$ & $193,05(165,51-220,59)$ & $195,56(167,38-223,74)$ & $191,82(165,09-218,55)$ & 216,67 \\
$01 / 10 / 2020$ & $193,05(163,84-222,26)$ & $195,87(165,91-225,84)$ & $193,39(165,12-221,66)$ & \\
$01 / 11 / 2020$ & $193,05(162,26-223,84)$ & $196,19(164,52-227,86)$ & $197,97(168,25-227,68)$ & \\
$01 / 12 / 2020$ & $193,05(160,76-225,34)$ & $196,50(163,20-229,81)$ & $196,04(164,95-227,13)$ & \\
$01 / 01 / 2021$ & $193,05(159,33-226,77)$ & $196,82(161,94-231,69)$ & $193,05(160,71-225,39)$ \\
\hline
\end{tabular}

Fonte: elaborada pelos autores com base nos resultados da pesquisa.

Considerando os valores observados para a arroba do boi gordo, nota-se que estava em torno de $R \$ 196,00$ até o mês de maio, ou seja, a diferença entre o previsto dos diferentes modelos e o observado não ultrapassou $R \$ 7,00$ nesse período. Entretanto, a partir de junho, o preço ultrapassou os $R \$ 200,00$, sendo que, em setembro, a diferença com relação à estimativa foi de mais de $R \$ 20,00$. Destaca-se que, considerando as previsões para 2020, os três modelos subestimaram os valores para o período. No entanto, os preços praticados nos meses comparados estão no intervalo de confiança de todos os modelos, o que indica a adequabilidade da metodologia para projetá-los.

Os preços praticados acima daqueles projetados para os meses de janeiro a setembro de 2020 podem ser justificados pelo aumento do volume de exportações para a China e pela redução da oferta de bovinos no mercado. De acordo com dados da Associação Brasileira das Indústrias Exportadoras de Carne (2019), o volume de exportação de carne bovina para a China aumentou em 54\% do ano de 2018 para 2019. Ainda, houve um crescimento de 116\% com relação às exportações do período de janeiro a setembro de 2020 em relação ao mesmo período de 2019.

Quanto à diminuição da oferta de animais, a quantidade de fêmeas foi reduzida nos últimos anos por causa do abate. De acordo com o Instituto Brasileiro de Geografia e Estatística (2020), nos meses de janeiro a junho de 2020, 14,55 milhões de cabeças de gado no Brasil foram abatidas, isto é, $8,63 \%$ menos que no mesmo período de 2019 , e a quantidade mais baixa desde 2011. A reposição das matrizes ficou cara, e, dessa forma, os criadores diminuíram a oferta de vacas e seguraram as novilhas para recompor o rebanho. O preço médio da carne bovina (para os cortes patinho, coxão mole e coxão duro) passou de $R \$ 20,56$ de janeiro a julho 2019 para $R \$ 25,37$ nos mesmos meses de 2020, conforme dados do Departamento Intersindical de Estatística e Estudos Socioeconômicos (2020). Além dos fatores citados, a redução dos

${ }^{4}$ Valores corrigidos para a base de janeiro de 2020 pelo IGP-DI. 
estoques da indústria frigorífica para o abastecimento do mercado interno durante a pandemia relacionada à Covid-19 também contribuiu para o aumento desse produto. Isso ocorreu tanto por restrições no funcionamento dos frigoríficos quanto pelo fato de as indústrias acreditarem que a demanda interna diminuiria significativamente durante a pandemia, o que não ocorreu.

Para avaliar as três métricas de qualidade da previsão, nota-se, na Tabela 3, que os menores valores foram observados para o modelo $2(10,03,7,69$ e 3,70 para o RMSE, MAE e MAPE, respectivamente), sendo que esse modelo foi o que apresentou as maiores previsões durante todo o período considerado, mostrando-se o mais adequado à projeção segundo os critérios relacionados à qualidade da estimativa.

Tabela 3. Medidas de avaliação da previsão dos modelos propostos

\begin{tabular}{cccc} 
Métrica & Modelo $\mathbf{1}$ & Modelo 2 & Modelo $\mathbf{3}$ \\
RMSE & 11,51 & 10,03 & 13,77 \\
MAE & 9,10 & 7,69 & 11,66 \\
MAPE & 4,39 & 3,70 & 5,66 \\
\hline
\end{tabular}

Fonte: elaborada pelos autores com base nos resultados da pesquisa. Nota: RMSE = Raiz do Erro Quadrático Médio; MAE = Erro Médio Absoluto; MAPE = Média do Erro Absoluto Percentual.

Quanto à análise do modelo de ajuste mais apropriado, pelos critérios AIC e BIC, que avaliam a qualidade do ajuste, o modelo 3 (tendência e sazonalidade) foi o mais indicado. Contudo, pelos critérios RMSE, MAE e MAPE, que avaliam a qualidade da projeção, o modelo 2 (tendência) teve um melhor desempenho na comparação do valor observado com relação ao previsto para o ano de 2020.

\subsubsection{Correlação cruzada}

Por fim, a relação do valor da arroba do boi gordo com outras variáveis de interesse foi avaliada pela metodologia de correlação cruzada, sendo os resultados apresentados na Figura 5.

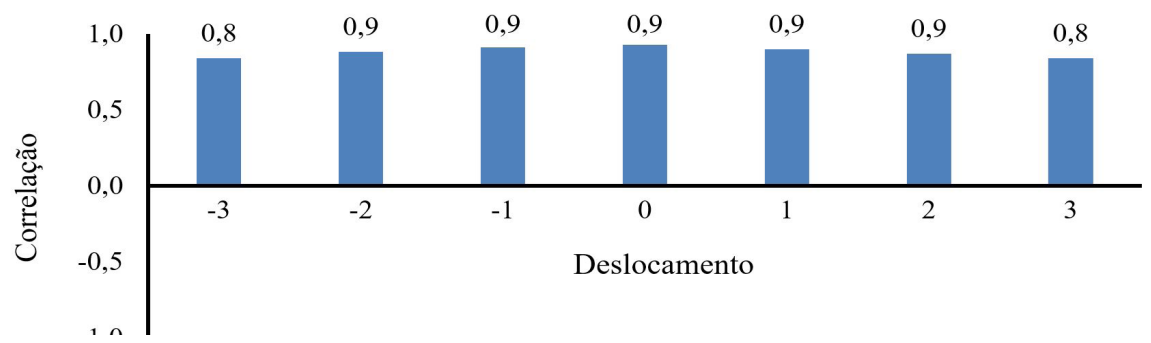

Figura 5. Correlação cruzada do preço do bezerro com o valor da arroba do boi gordo. Fonte: elaborada pelos autores com base nos resultados da pesquisa.

Nota-se claramente que o valor por cabeça do bezerro apresenta uma forte correlação com o valor da arroba do boi gordo, chegando a um coeficiente de correlação de Pearson de 0,93 no deslocamento 0 , diminuindo levemente para 0,84 nos deslocamentos -3 e $3^{5}$. Dessa maneira, pode-se concluir que o preço do bezerro é fortemente influenciado pelo preço da arroba do boi gordo (Osaku, 2019).

${ }^{5}$ Quanto à intensidade da correlação, consideraram-se os valores entre 0,1 e 0,4 como fraca, entre 0,4 e 0,7 como moderada e, por fim, entre 0,7 e 0,9 como forte. Os valores valem para casos positivos e negativos. Se a correlação for igual a 1, ela é denominada correlação perfeita; se a correlação for igual a 0, é denominada nula. 
A atividade pecuária é caracterizada por períodos cíclicos anuais e plurianuais, ocorrendo variações nos preços conforme a sazonalidade da produção. Quando há uma grande oferta de boi gordo, ocorre uma queda no preço da arroba, fator que pressiona o pecuarista a abater as matrizes ${ }^{6}$. Dessa forma, a menor disponibilidade de matrizes leva à baixa produção de bezerros, o que reflete na redução da oferta do boi gordo futuramente e contribui para o aumento do preço da arroba do boi no médio e longo prazo. Nessa fase, o preço do bezerro sofre forte influência por causa da expectativa de alta do preço no mercado (Sachs \& Martins, 2007).

Outra variável que apresentou uma forte correlação com o preço da arroba do boi gordo foi a relação de troca boi gordo/boi magro, conforme a Figura 6.

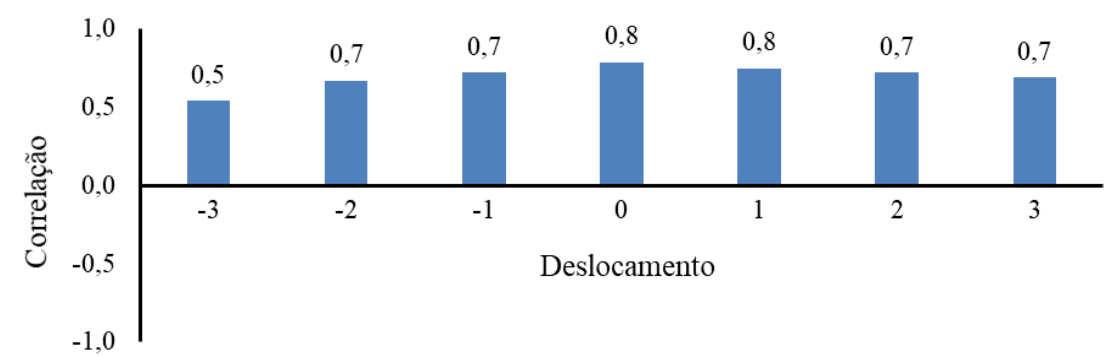

Figura 6. Correlação cruzada da relação de troca boi gordo/boi magro com o valor da arroba do boi gordo. Fonte: elaborada pelos autores com base nos resultados da pesquisa.

A relação de troca entre o boi gordo e o boi magro se deve em parte pelo fato de os bovinos que são destinados ao abate serem criados sob o regime de confinamento, principalmente no período de entressafra, que ocorre durante a estação de seca. Esse método é visto como um complemento à pastagem, pois permite a engorda do boi destinado ao abate ao longo do ano inteiro e necessita de menor tempo para que o animal chegue ao peso ideal. Além disso, o boi magro é responsável por cerca de $63 \%$ do custo do confinamento (Ziliotto et al., 2010).

Ainda, a correlação positiva entre o preço da arroba do boi gordo e o volume de abates de bovinos, representada na Figura 7, reforça o ciclo anual da pecuária brasileira, cuja produção é, principalmente, natural, extensiva e sazonal, conforme as estações de reprodução do gado, dividindo-se nos períodos de safra e entressafra (Medeiros, 2006).

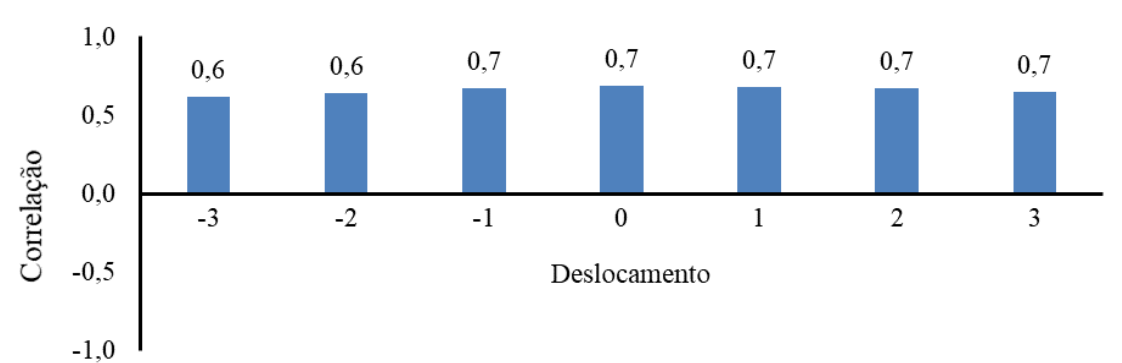

Figura 7. Correlação cruzada do abate de bovinos no Brasil com o valor da arroba do boi gordo. Fonte: elaborada pelos autores com base nos resultados da pesquisa.

${ }^{6}$ O envio de uma maior quantidade de fêmeas para abate se justifica pelo fato de os valores da venda dos bezerros não suprirem as despesas da propriedade quando o preço da arroba está baixo, assim como para fazer caixa em um momento de redução da receita (Pinatti, 2008). 
Além disso, avaliou-se a correlação da importação de carne bovina brasileira pela China e a exportação de carne bovina pelos Estados Unidos (Figura 8), visto que ambos os países possuem uma posição de destaque nesse mercado.

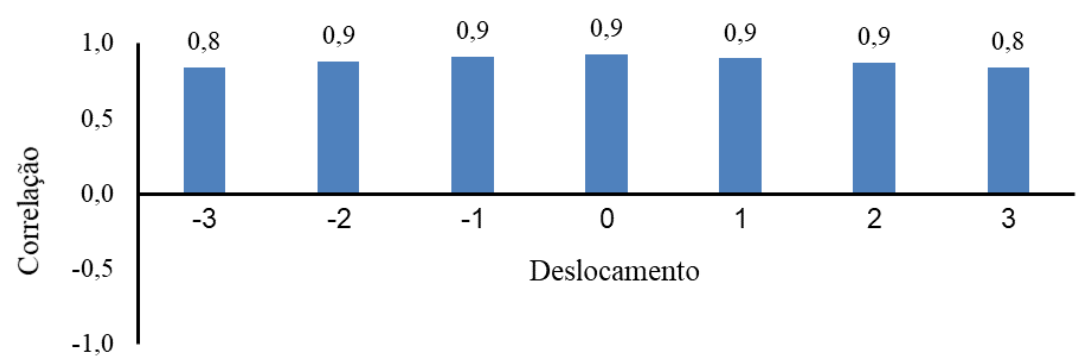

Figura 8. Correlação cruzada da importação de carne bovina brasileira pela China com o valor da arroba do boi gordo. Fonte: elaborada pelos autores com base nos resultados da pesquisa.

Segundo os dados da Associação Brasileira das Indústrias Exportadoras de Carne (2019), a China é o principal importador da carne bovina brasileira atualmente, sendo responsável pela importação de $43,73 \%$ do volume em toneladas no último ano, considerando o período de julho de 2019 a junho de 2020. Ao adicionar Hong Kong, segundo maior importador e território autônomo a sudeste da China, esse percentual chega a 59,69\% do volume de exportação. Desde 2017, China e Hong Kong se mantêm nos dois primeiros lugares do "ranking" de importação de carne bovina brasileira. A principal barreira técnica imposta pela China para a importação de carne bovina é a encefalopatia espongiforme bovina (BSE), sendo que a Organização Mundial de Saúde Animal (OIE) classifica o Brasil como um produtor de baixo risco de BSE, fato que influencia o aumento das importações de carne brasileira pela China (Florindo et al., 2015). As estatísticas apresentadas corroboram a forte correlação positiva verificada entre o preço da arroba do boi gordo e o volume de importação de carne bovina brasileira pela China.

O gráfico da Figura 9 aponta a correlação entre a exportação de carne bovina por parte dos Estados Unidos e o preço da arroba do boi gordo no Brasil.

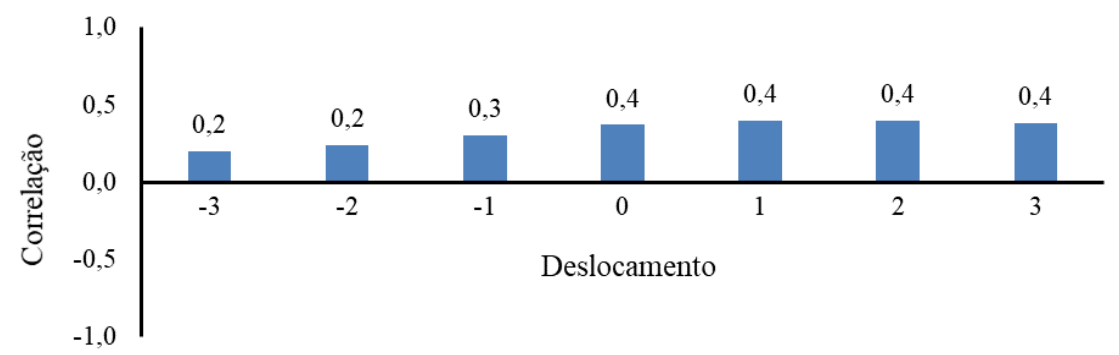

Figura 9. Correlação cruzada da exportação de carne bovina dos Estados Unidos com o valor da arroba do boi gordo. Fonte: elaborada pelos autores com base nos resultados da pesquisa.

No que se refere à produção de carne bovina em âmbito mundial, o "forecast" para 2020, publicado em abril pelo United States Department of Agriculture (2020), indica os Estados Unidos como o maior produtor com 20,3\% de "market share", seguido pelo Brasil (16,8\%), União Europeia (12,7\%) e China (11,3\%). A China, apesar de sua considerável produção, é uma grande consumidora e importadora de carne mundial, responsável por cerca de $29 \%$ da importação nesse segmento. Ainda, o United States Department of Agriculture (2020) aponta 
o Brasil como o maior exportador, com $23,4 \%$ da fatia desse mercado, seguido pelos Estados Unidos, com 13,4\%.

Visando averiguar o impacto de uma possível concorrência na exportação de carne bovina entre os Estados Unidos e o Brasil, calculou-se a correlação desta com o preço da arroba brasileira, obtendo-se uma indicação positiva, porém de intensidade moderada, pois a maior parte do volume exportado por esses países tem destinos diferentes. De acordo com dados da U.S. Meat Export Federation (2019), no ano de 2019, os principais importadores de carne dos Estados Unidos foram Japão, Coreia, México e Canadá, que, juntos, representaram em torno de $72 \%$ do volume de exportações de carne bovina dos Estados Unidos. No entanto, segundo a Associação Brasileira das Indústrias Exportadoras de Carne (2019), os principais importadores de carne bovina brasileira foram China, Hong Kong, Egito e Chile, representando, somados, cerca de 60\% das exportações de carne bovina brasileiras em 2019.

Por fim, a última variável analisada foi o dólar americano, que apresenta correlação negativa com o valor da arroba do boi gordo em reais (Figura 10), sendo que, embora moderada, sua força aumenta para deslocamentos maiores.

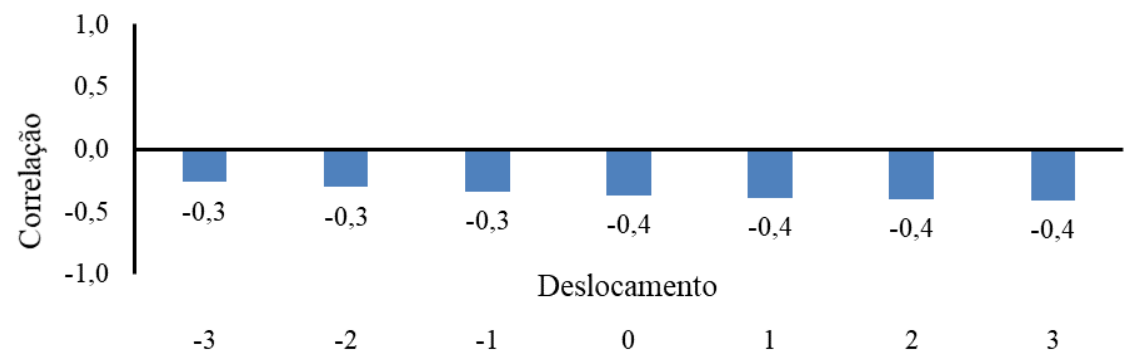

Figura 10. Correlação cruzada da cotação do dólar com o valor da arroba do boi gordo. Fonte: elaborada pelos autores com base nos resultados da pesquisa.

A menor correlação no curto prazo pode estar relacionada a operações de hedge, que protegem contra a exposição das variações cambiais em um prazo menor, todavia perdem a eficiência no longo prazo (Aguiar, 2016). Esse resultado vai ao encontro daqueles obtidos por Tonello et al. (2011) e Lima (2019) em estudos relacionados ao tema.

Lima (2019), em sua análise, aponta que, em 2018, considerando toda a produção de carne bovina brasileira, apenas $20,4 \%$ foram exportadas e $79,6 \%$ tiveram como destino o mercado interno. Dados atuais da Associação Brasileira das Indústrias Exportadoras de Carne (2019) referente ao ano de 2019 indicam que essa proporção continua válida. Assim sendo, apesar de o dólar em alta impulsionar as exportações de carne bovina, a desvalorização da moeda real em relação ao dólar pode indicar um fraco desempenho da economia nacional quando comparada à economia americana e à liquidez do mercado internacional, refletindo o desaquecimento do mercado consumidor interno de carne bovina - que representa o destino majoritário dos abates. Nessa situação, é comum o aumento do consumo da carne de frango e da carne suína, sendo produtos substitutos e com preço inferior ao da carne bovina (Pindyck \& Rubinfeld, 2005). Ainda, em análise realizada por Silva Filho et al. (2005), verificou-se que uma variação positiva de $1 \%$ no preço da carne bovina aumentava em $0,18 \%$ a quantidade da demanda pela carne suína, reforçando que esses produtos são substitutos para o consumidor brasileiro. Silva et al. (2020) também comprovam em seu estudo que há uma forte correlação linear positiva entre os preços das carnes bovina, suína e de frango no mercado nacional, ocorrendo a transmissão de preços entre elas. 


\section{CONCLUSÕES}

O objetivo geral deste estudo foi verificar a projeção da tendência do preço da arroba do boi gordo no curto prazo com o uso de MLD. Observou-se que o modelo para ajuste da série temporal denominado tendência e sazonalidade apresentou a melhor avaliação no critério qualidade do ajuste, por englobar o comportamento cíclico próprio da pecuária de corte. No entanto, o modelo tendência mostrou-se o mais adequado para a projeção do preço no ano de 2020, com um aumento linear de $\mathrm{R} \$ 0,31$ ao mês. Em ambos os modelos, os valores reais do período analisado constavam no intervalo de confiança das projeções, o que indica um adequado ajuste do MLD.

As variáveis analisadas que possuem maior correlação com o valor da arroba do boi gordo são o preço do bezerro, a relação de troca boi gordo/boi magro, o abate de bovinos no Brasil e a importação de carne bovina brasileira pela China, por ser o país com maior volume de importação desse produto. Já as variáveis que tiveram correlação moderada foram a taxa de câmbio do dólar americano e a exportação de carne bovina pelos Estados Unidos, visto que, apesar de ser o segundo maior exportador mundial de carne bovina, os principais destinos de exportação não coincidem com os do Brasil até o momento deste estudo.

Portanto, conclui-se que o preço da arroba do boi gordo pode ser estimado no curto prazo por meio do método univariado MLD com um nível de acurácia aceitável. O indicador apresentou uma tendência real de crescimento ao longo do período analisado, o que pode indicar uma tendência futura de alta nos preços. No entanto, existem limitações, visto que há possibilidade de ocorrerem mudanças no cenário macroeconômico que não são previstas no modelo.

\section{REFERÊNCIAS}

Aguiar, H. M. (2016). Efeitos de variáveis macroeconômicas no preço do boi gordo no Estado de São Paulo (Dissertação de mestrado). Fundação Getúlio Vargas, São Paulo.

Associação Brasileira das Indústrias Exportadoras de Carne - ABIEC. (2019). Exportações. Recuperado em 6 de julho de 2020, de http://abiec.com.br/exportacoes/

Associação Brasileira das Indústrias Exportadoras de Carne - ABIEC. (2020). Exportações. Recuperado em 6 de julho de 2020, de http://abiec.com.br/exportacoes/

Ávila, M. M. (2015). Economic viability of production systems in full cycle of beef cattle(Dissertação de mestrado). Universidade Federal de Santa Maria, Santa Maria.

Banco Central do Brasil - BCB. (2020). Cotação e boletins. Recuperado em 11 de maio de 2020, de https://www.bcb.gov.br/

Box, G. E. P., \& Tiao, G. C. (1975). Intervention analysis with applications to economic and environmental problems. Journal of the American Statistical Association, 70(349), 70-79.

Bressan, A. A. (2004). Tomada de decisão em futuros agropecuários com modelos de previsão de séries temporais. RAE Eletrônica, 3(1), 2-20.

Bressan, A. A., \& Lima, J. E. (2002). Modelos de previsão de preços aplicados aos contratos futuros de boi gordo na BM\&F. Nova Economia, 12(1), 117-140.

Buainain, A. M., \& Batalha, M. O. (2007). Cadeia produtiva de carne bovina (Vol. 8). Brasília: Ministério da Agricultura, Pecuária e Abastecimento. Recuperado em 20 de dezembro de 2020, de http://repiica.iica.int/docs/b0585p/b0585p.pdf 
Centro de Estudos Avançados em Economia Aplicada - CEPEA. (2020a). Indicador do Bezerro. ESALQ. Recuperado em 11 de maio de 2020, de https://www.cepea.esalq.usp.br/br/ indicador/bezerro.aspx

Centro de Estudos Avançados em Economia Aplicada - CEPEA. (2020b). Consultas ao banco de dados do site. Recuperado em 11 de maio de 2020, de https://www.cepea.esalq.usp. $\mathrm{br} / \mathrm{br} / \mathrm{consultas-ao-banco-de-dados-do-site.aspx}$

Cezar, I. M., Queiroz, H. P., Thiago, L. R. L. S., Garagorry, F. L., \& Costa, F. P. (2005). Sistemas de produção de gado de corte no Brasil: uma descrição com ênfase no regime alimentar e no abate. Campo Grande: Embrapa Gado de Corte. Recuperado em 21 de dezembro de 2020, de https://www.infoteca.cnptia.embrapa.br/infoteca/handle/doc/326307

DeLurgio, S. A. (1998). Forecasting principles and applications. Boston: McGrawHill.

Departamento Intersindical de Estatística e Estudos Socioeconômicos - DIEESE. (2020). Inflação e preços. Recuperado em 14 de setembro de 2020, de https://www.dieese.org.br/

Empresa Brasileira de Pesquisa Agropecuária - EMBRAPA. (2019). Pastagem. Recuperado em 21 de dezembro de 2021, de https://www.embrapa.br/qualidade-da-carne/carne-bovina/ producao-de-carne-bovina/pastagem

Federação das Indústrias do Estado de São Paulo - FIESP. (2020). Projeções para o agronegócio brasileiro: 2029. Recuperado em 22 de dezembro de 2020, de https://outlookdeagro. azurewebsites.net/OutLookDeagro/pt-BR/Impresso

Ferreira, M. A., Valadares Filho, S. C., Muniz, E. B., \& Veras, A. S. C. (2000). Características das carcaças, biometria do trato gastrintestinal, tamanho dos órgãos internos e conteúdo gastrintestinal de bovinos F1 Simental x Nelore alimentados com dietas contendo vários níveis de concentrado. Revista Brasileira de Zootecnia, 29(4), 1174-1182.

Florindo, T. J., Medeiros, G. I. B., \& Mauad, J. R. D. (2015). Análise das barreiras não tarifárias à exportação da carne bovina. Revista de Política Agrícola, 24(2), 52-63.

Food and Agriculture Organization of the United Nations - FAO. (2015). Food outlook: biannual report on global food markets. New York: FAO.

Fundação Getúlio Vargas - FGV. (2020). IGP. Recuperado em 15 de abril de 2020, de https:// portalibre.fgv.br/estudos-e-pesquisas/indices-de-precos/igp

Gaio, L. E., Castro Junior, L. G., \& Oliveira, A. R. (2005). Causalidade e elasticidade na transmissão de preço do boi gordo entre regiões do Brasil e a Bolsa de Mercadorias e Futuros (BM\&F). Organizações Rurais \& Agroindustriais, 7(3), 282-297.

Instituto Brasileiro de Geografia e Estatística - IBGE. (2020). Pesquisa trimestral do abate de animais. Recuperado em 11 de maio de 2020, de https://www.ibge.gov.br/estatisticas/ economicas/agricultura-e-pecuaria/9203-pesquisas-trimestrais-do-abate-de-animais. html?=\&t=o-que-e

Instituto de Economia Agrícola - IEA. (2019). Relação de troca produtos/insumos. Recuperado em 11 de maio de 2020, de http://ciagri.iea.sp.gov.br/nia1/RelaTrocaProduto.aspx?cod_sis=22

Instituto FNP. (2015). Anuário da pecuária brasileira. São Paulo: Agra FNP Pesquisas Ltda.

Lazzarini Neto, S. (2000). Manejo de pastagens (2. ed.). Viçosa: Aprenda Fácil.

Lima, M. M. (2019). Fatores determinantes do preço da arroba do boi gordo (Dissertação de mestrado). Universidade Estadual Paulista, Jaboticabal.

Malafaia, G. C. (2013). As interações entre os agentes da cadeia produtiva da pecuária de corte no Brasil: implicações para a sustentabilidade. Campo Grande: Embrapa Gado de Corte. 
Marion, J. C. (2016). Contabilidade rural. São Paulo: Atlas.

Medeiros, A. L. (2006). Regressão múltipla e o modelo ARIMA na previsão do preço da arroba do boi gordo (Dissertação de mestrado). Universidade Federal de Itajubá, Itajubá.

Medeiros, A. L., \& Montevechi, J. A. B. (2005). Modedeslocamentoem da equação de previsão do preço da arroba de boi gordo através da regressão linear múltipla. In Anais do $12^{\circ}$ Simpósio de Pós-graduação em Engenharia de Processos. Bauru.

Montgomery, D. C., Jennings, C. L., \& Kulahci, M. (2008). Introduction to time series analysis and forecasting (6. ed.). New Jersey: Wiley-Interscience.

Osaku, C. Y. (2019). Transmissão de preços entre animais vivos e terminados nos mercados bovino e suíno no Estado de São Paulo (2013-2018)(Dissertação de mestrado). Universidade Estadual de Ponta Grossa, Ponta Grossa.

Petris, G. (2010). An R package for dynamic linear models. Journal of Statistical Software, 36(12), 1-16.

Petris, G., Campagnoli, P., \& Petrone, S. (2009). Dynamic linear models with R. New York: Springer-Verdeslocamento.

Pinatti, E. (2008). Efeitos das cotações do dólar comercial e do índice pluviométrico sobre os preços do boi gordo no estado de São Paulo, no período após plano real. Revista de Economia Agrícola, 55(1), 77-88.

Pindyck, R. S., \& Rubinfeld, D. (2005). Microeconomia. São Paulo: Makron Books.

Pires, J. A. A. (2011). A cadeia produtiva de carne bovina no Brasil: mercado internacional e nacional. In Anais do $3^{\circ}$ Simpósio de Produção de Gado de Corte. Viçosa.

R Development Core Team. (2015). R: a language and environment for statistical computing. Vienna: R Foundation for Statistical Computing. Recuperado em 2 de março de 2020, de http://www.R project.org

Sabadin, C. (2006). O comércio internacional da carne bovina brasileira e a indústria frigorífica exportadora (Dissertação de mestrado). Universidade Federal de Mato Grosso do Sul, Campo Grande.

Sachs, R. C. C., \& Martins, S. S. (2007). Análise do comportamento dos preços do boi gordo e do bezerro na pecuária de corte paulista, janeiro de 1995 a abril de 2006: uma aplicação do modelo VAR. Revista de Economia Agrícola, 54(1), 75-85.

Sachs, R. C. C., \& Pinatti, E. (2007). Análise do comportamento dos preços do boi gordo e do boi magro na pecuária de corte paulista, no período de 1995 a 2006. Revista de Economia e Agronegócio, 5(3), 329-352.

Santos, G. J., Marion, J. C., \& Segatti, S. (2009). Administração de custos na agropecuária (4. ed.). São Paulo: Atlas.

Santos, J. C., \& Gomes, S. C. (2006). Padrões sazonal e cíclico para preço de boi gordo no estado de São Paulo. 1976-2004. In Anais do $44^{\circ}$ Congresso Brasileiro de Sociedade Brasileira de Economia, Administração e Sociologia Rural. Fortaleza.

Silva Filho, L., Moretto, A. C., \& Ferreira, C. R. (2005). O mercado de carne suína no Paraná: análise de oferta e demanda. In Anais do $43^{\circ}$ Congresso Brasileiro de Sociedade Brasileira de Economia, Administração e Sociologia Rural. Ribeirão Preto.

Silva, A. C., Oliveira Neto, O. J., \& Figueiredo, R. S. (2020). Mercado brasileiro de carnes: transmissão de preços. Brazilian Journal of Development, 6(3), 15870-15892. 
Teixeira, J. C., \& Hespanhol, A. H. (2014). A trajetória da pecuária bovina brasileira. Caderno Prudentino de Geografia, 1, 26-38.

Thiago, L. R. L. S., \& Costa, F. P. (1994). Confinamento na prática: sistemas alternativos (Comunicado Técnico, No. 50). Campo Grande: EMBRAPA-CNPGC.

Tonello, C. L., Pasquetti, T. J., Barbosa, O. R., Bueno, L., \& Höring, C. F. (2011). Determinantes do preço do boi gordo no Estado de São Paulo. Recuperado em 5 de julho de 2020, de https:// pt.engormix.com/pecuaria-corte/artigos/determinantes-preco-boi-gordo-t37167.htm

U.S. Meat Export Federation - USMEF. (2019). Export statistics. Recuperado em 11 de maio de 2020, de https://www.usmef.org/usmef-statistics-and-trade-access/export-statistics/

United States Department of Agriculture - USDA. (2020). Foreign agricultural service: market and trade data, PSD online. Recuperado em 2 de julho de 2020, de https://apps.fas.usda. gov/psdonline/app/index.html\#/app/topCountriesByCommodity

Zen, S., Menezes, S. M., \& Carvalho, T. B. (2008). Perspectivas de consumo de carne bovina no Brasil. In Anais do $46^{\circ}$ Congresso da Sociedade Brasileira de Economia, Administração e Sociologia Rural. Rio Branco.

Ziliotto, M. R., Silveira, C., Camargo, M. E., Motta, M. E. V., \& Priesnitz Filho, W. (2010). Comparação do custo de produção de bovinocultura de corte: pasto versus confinamento. In Anais do $7^{\circ}$ Simpósio de Excelência em Gestão e Tecnologia. Rio de Janeiro. 